\title{
Outcomes of resectable pulmonary aspergilloma and the performance gap in a high tuberculosis prevalence setting: A retrospective study
}

\author{
S R Masoud, ${ }^{1} \mathrm{MD}$, MMed; E M Irusen, ${ }^{1} \mathrm{MB}$ ChB, FCP (SA), PhD; C F N Koegelenberg, ${ }^{1} \mathrm{MB}$ ChB, MMed (Int), FCP (SA), FRCP (UK), \\ Cert Pulm, PhD; L J du Preez, ${ }^{2}$ MB ChB, DA (SA), FCS (SA), FCA (SA); B W Allwood, ${ }^{1}$ MB ChB, MPH, FCP (SA), Cert Pulm (SA), PhD
}

\author{
${ }^{1}$ Division of Pulmonology, Department of Internal Medicine, Faculty of Medicine and Health Sciences, Stellenbosch University and Tygerberg Academic Hospital, \\ Cape Town, South Africa \\ ${ }^{2}$ Cardiothoracic Surgery, Department of Surgery, Faculty of Medicine and Health Sciences, Stellenbosch University and Tygerberg Academic Hospital, Cape Town, \\ South Africa
}

Corresponding author: S R Masoud (salcolmx@gmail.com)

\begin{abstract}
Background. Pulmonary aspergillomas develop in patients with underlying structural lung diseases. The mainstay of therapy is surgery. Objectives. To assess treatment and clinical outcomes following diagnosis of potentially resectable pulmonary aspergilloma at the Tygerberg Hospital (TBH) between January 2013 and December 2015.

Methods. This was a retrospective analysis conducted at TBH. Patients were followed up between 6 and 29 months following diagnosis to analyse outcomes.

Results. Fifty-nine patients presented for surgery. The mean (SD) age was 44.5 (8.8) years. Thirty-six (61.0\%) were male and 13 (22.0\%) were HIV-positive. A previous history of pulmonary TB was identified in $83.1 \%$ of the patients. One or both upper lobes were involved in 58 patients (98.3\%) and haemoptysis was the most frequent symptom, occurring in 56 patients (94.9\%). Nine patients (15.3\%) were considered unfit for surgery. As of June 2016, 23 (46.0\%) of the remaining 50 patients had undergone surgery and 3 (6.0\%) had died before surgery was performed. The median time from multidisciplinary discussion to surgery was 190 days (interquartile range 134 - 351). Twenty patients (87.0\%) underwent lobectomy and $3(13.0 \%)$ had pneumonectomy. There was no postoperative mortality. One patient developed bleeding, persistent air leak and aspiration pneumonia postoperatively. Three patients were hospitalised for $>7$ days postoperatively. Following surgery, only two patients reported ongoing respiratory symptoms by day 90 .

Conclusion. Less than half of the patients accepted for lung resection at TBH underwent surgery. Waiting times were long (>1 year in $25 \%)$ and were associated with mortality. Barriers to prompt surgery are complex, but should be addressed urgently.
\end{abstract}

S Afr Respir J 2017;23(1):8-13. DOI:10.7196/SARJ.2017.v23i1.154

Aspergillus is a ubiquitous fungus that causes a variety of clinical syndromes in the lung. Aspergilloma, which is the most common and best-recognised form of pulmonary involvement consists of masses of fungal mycelia, inflammatory cells, fibrin, mucus, and tissue debris, usually developing in preformed lung cavities. ${ }^{[1]}$

The true incidence of aspergilloma is not known. In a study of 544 patients with pulmonary cavities secondary to tuberculosis (TB), 22\% had radiological evidence of aspergilloma. ${ }^{[2]}$ The natural history of aspergilloma is variable. In the majority of cases, the lesion remains stable; however, in $\sim 10 \%$ of cases, it may decrease in size or resolve spontaneously without treatment. ${ }^{[3,4]}$ An aspergilloma may be asymptomatic for years, although some patients experience minor haemoptysis. Severe haemoptysis may occur, with associated mortality rates between 2 and $14 \% \cdot{ }^{[5-10]}$ Radiologically, an aspergilloma is classically a mobile, intracavitary mass surrounded by an air crescent, but it may also be an immobile ball, an irregular spongelike opacity containing air spaces, or even a network of fungal strands within cavities. ${ }^{[11]}$

Medical treatment of aspergillomas with antifungal agents may be useful in preventing or treating life-threatening haemoptysis, and is considered the standard care for complex aspergilloma, also known as chronic cavitating pulmonary aspergillosis. ${ }^{[12]}$ Bronchial artery embolisation is frequently used as a temporising measure in patients with life-threatening haemoptysis; however, relapse occurs in $~ 50 \%$ of patients. ${ }^{[13,14]}$

Surgical resection is the definitive treatment for patients with adequate pulmonary reserve and should be considered in all patients with severe haemoptysis. It has the benefits of prevention of lifethreatening haemoptysis, eradication of the pyogenic component and probable prolongation of life. ${ }^{[15-21]}$ Although surgical resection is considered curative, it is not possible in every patient, for a variety of physiological and technical reasons. Such reasons may include poor physical condition, severe comorbidity, poor pulmonary reserve, extensive lung involvement or inability to localise the bleeding site. Furthermore, the thoracic surgical expertise needed to perform lung resection is often limited or unavailable in low- and middle-income countries such as South Africa (SA), where aspergillomas are most common. The purpose of our study was to retrospectively review all cases of aspergilloma accepted for surgical resection at our tertiary hospital between January 2013 and December 2015, to assess outcomes.

\section{Methods}

Participants were retrospectively included in the study if they were: (i) at least 18 years old; (ii) diagnosed with pulmonary aspergilloma; 
and (iii) presented at a multidisciplinary forum at Tygerberg Hospital (TBH) between January 2013 and December 2015 for possible lung resection based on the European Respiratory Society's guidelines. ${ }^{[22,23]}$ In order to be presented for surgical resection at this forum, local protocol requires that the patient must have debilitating and/or severe and potentially life-threatening symptoms necessitating the surgery (for example, major haemoptysis or intractable pain), and in addition all patients should be deemed amenable to surgical resection by the attending pulmonologist.

Data for identified cases were collected from encounters in the chronological registers up to the end of May 2016. The hospital medical records were searched both manually and electronically for documents in hard copy and in digital format, respectively. Ethical approval for the study was obtained from the Stellenbosch University research ethics committee (ref. no. S15/07/158).

The data were captured and coded in Microsoft Office Excel 2016 (USA) before analysis using STATA 14 statistical software (StataCorp, USA). Continuous data were tested for normality using histogram plots and the Shapiro-Wilk test. For normally distributed data, means and standard deviations (SDs) were reported, while medians and interquartile ranges (IQRs) were reported for data that were not normally distributed. For categorical data, frequencies and proportions were reported.

For all estimations, 95\% confidence intervals (CIs) were reported. All significance tests for comparisons were two-sided and carried out with an alpha value of 0.05 . The $t$-test and Mann-Whitney $U$-test were used for comparisons between numerical data, whereas the $\chi^{2}$ test and Fisher's exact test were used for categorical variables.

\section{Results}

Between January 2013 and December 2015, 59 patients with pulmonary aspergilloma were presented to a weekly multidisciplinary forum at $\mathrm{TBH}$ for possible lung resection. Almost all the patients (98\%) were recruited. The patients had a mean (SD) age of $44.5(8.8)$ years, (range 27.4 - 66.3 years). Most patients were male (61\%), and resided within the city of Cape Town municipality (52.5\%) or the neighbouring Cape Winelands, a peri-urban municipality (44.1\%) (Table 1). Thirteen patients (22\%) were HIV-positive.

A previous history of pulmonary TB was reported in $83 \%$ of patients, and the majority (95\%) of the patients presented with major haemoptysis requiring admission, while a minority (14\%) reported chest pain and coughing, with or without haemoptysis. All patients presented to the forum were subjected to chest radiography, computed tomography (CT) of the chest and spirometry, and 75\% underwent cardiopulmonary exercise testing as part of the workup for possible lung resection. Seventeen percent of the patients were categorised as having simple aspergilloma on CT and the remaining as complex aspergilloma according to criteria by Belcher and Plummer. ${ }^{[15]}$ Most patients (89.9\%) had involvement of a single lobe, and the majority (98.3\%) had involvement of the upper lobes of either lung, with approximately equal involvement of the left upper (50.9\%) and right upper lobes (47.5\%) (Table 1). Eleven patients reported ongoing respiratory symptoms 90 days after the multidisciplinary discussion.

Nine patients (15.3\%) were found to be unfit for surgery owing to poor lung function and high surgical risk. The characteristics of these
Table 1. Demographic characteristics

\begin{tabular}{ll}
\hline Characteristic & $\boldsymbol{n}(\%)^{\star}$ \\
\hline $\begin{array}{l}\text { Age (years), mean (SD) } \\
\text { Sex }\end{array}$ & $44.5(8.8$ \\
$\quad$ Male & $36(61.0)$ \\
Female & $23(39.0)$ \\
Residence & \\
City of Cape Town & $31(52.5)$ \\
Cape Winelands & $26(44.1)$ \\
Other & $2(3.4)$
\end{tabular}

Symptoms

Haemoptysis

$56(94.9)$

Chest pain

Cough

Weight loss

Shortness of breath

Lobar involvement

LUL

RUL

RUL + LUL

LUL + LLL

RUL + LLL

LLL

Type of disease

Simple

Complex

$49(83.0)$

Previous history of TB

$49(83.0)$

HIV status

Negative

Positive

$13(22.0)$

Unknown

$5(8.5)$

FEV1 (L/s), mean (SD)

$1.83(0.72)$

Predicted \% of FEV1, mean (SD)

$59.3(19.5)$

DLCO ( $\mathrm{mL} / \mathrm{min} / \mathrm{mmHg})$, mean (SD)

$16.1(5.1)$

Predicted \% of DLCO, median (IQR)

$57.1(50.2-71.0)$

$\mathrm{VO}_{2} \max (\mathrm{mL} / \mathrm{min} / \mathrm{kg})$, mean (SD), $n=44$

Surgery

Performed

Not performed

$24(40.7)$

Unfit for surgery

$9(15.3)$

Died prior to surgery

DLCO = diffusion capacity for carbon monoxide; FEV1 = forced expiratory volume in the first second; $\mathrm{LLL}=$ left lower lobe; $\mathrm{LUL}=$ left upper lobe; $\mathrm{RLL}=$ right lower lobe; $\mathrm{RUL}=$ right upper lobe; $\mathrm{VO}_{2} \max =$ maximum oxygen uptake.

*Unless otherwise specified. 
patients are summarised in Table 2. They were relatively older than patients found fit for surgery (median age 47.6 v. 44.0 years) with significantly worse lung physiology. The mean (SD) forced expiratory volume in the first second (FEV1) and the mean (SD) diffusion capacity for carbon monoxide (DLCO) of those unfit for surgery were 1.03 (0.37) $\mathrm{L} / \mathrm{s}$ and 11.4 (3.6) $\mathrm{mmol} / \mathrm{min} / \mathrm{mmHg}$, respectively, whereas those for surgically fit patients were $1.98(0.67) \mathrm{L} / \mathrm{s}$ and 17.0 (4.9) $\mathrm{mmol} / \mathrm{min} / \mathrm{mmHg}$, respectively. One of the patients required embolisation for recurrent haemoptysis 20 months after the discussion, while the remaining eight were lost to follow-up.

The 50 patients accepted for surgery were electively booked for the procedure with a median duration of 99 days (IQR 92 - 113) before their surgery appointment. Twentythree of them (46\%) had had surgery by June 2016. There were no significant differences in the characteristics of those who underwent surgery and those who did not (Table 3).
Surgery was delayed in the majority of cases, with the median time from presentation to surgery being 190 days (IQR 134 - 351) among those who underwent surgery. Only three patients had surgery on the appointed day. The reason for delay or lack of surgery was not identified in the majority of patients. The identified reasons for delay among those who had surgery included miscommunication ( $n=1)$, hospital bed shortage $(n=1)$, missed appointment $(n=1)$ and lack of theatre time owing to competing emergency procedures $(n=1)$. Among those who did not undergo surgery, the identified reasons for delay included loss to follow-up ( $n=12)$, miscommunication $(n=1)$, withdrawal of consent $(n=2)$ and lack of transport $(n=1)$. One patient developed myocarditis due to systemic lupus erythematosus and another developed active pulmonary TB. Three patients died from unknown causes before undergoing surgery. Among those who did not undergo surgery, five remained symptomatic as at June 2016.

Table 2. Comparison between the surgically fit and unfit patients

\begin{tabular}{|c|c|c|c|}
\hline Characteristic & $\begin{array}{l}\text { Surgically fit } \\
(n=50), n(\%)^{*}\end{array}$ & $\begin{array}{l}\text { Surgically unfit } \\
(n=9), n(\%)^{*}\end{array}$ & $p$-value \\
\hline Age (years), median (IQR) & $\begin{array}{l}44.05(37.00- \\
49.78)\end{array}$ & $\begin{array}{l}47.63(45.95- \\
53.47)\end{array}$ & 0.066 \\
\hline Sex, male & $31(62)$ & $5(56)$ & 0.715 \\
\hline Residence & & & 0.847 \\
\hline City of Cape Town & $21(42)$ & $5(56)$ & \\
\hline Cape Winelands & $27(54)$ & $4(44)$ & \\
\hline Haemoptysis & $48(96)$ & $8(89)$ & 0.371 \\
\hline Lobe involvement & & & 0.127 \\
\hline LUL & $25(50)$ & $2(22)$ & \\
\hline RUL & $20(40)$ & $5(56)$ & \\
\hline RUL + RLL & $2(4)$ & 0 & \\
\hline LUL + LLL & 0 & $1(11)$ & \\
\hline RUL + LLL & $1(2)$ & 0 & \\
\hline LLL & $2(4)$ & $1(11)$ & \\
\hline Type of disease, complex & $40(80)$ & $9(100)$ & 0.141 \\
\hline HIV-positive & $11(22)$ & $2(22)$ & 0.605 \\
\hline FEV1 (L/s), mean (SD) & $1.98(0.67)$ & $1.03(0.37)$ & 0.0001 \\
\hline Predicted \% FEV1, mean (SD) & $63.3(17.3)$ & $37.2(16.6)$ & 0.0006 \\
\hline DLCO, mean (SD) & $17.0(4.9)$ & $11.4(3.6)$ & 0.0027 \\
\hline Predicted \% DLCO, mean (SD) & $61.4(16.1)$ & $43.8(9.5)$ & 0.0014 \\
\hline $\begin{array}{l}\mathrm{VO}_{2} \max (\mathrm{mL} / \mathrm{min} / \mathrm{kg}) \text {, mean } \\
(\mathrm{SD})\end{array}$ & $23.4(5.7)$ & $17.9(4.2)$ & 0.0161 \\
\hline
\end{tabular}

Among those who underwent surgery, $18(78.3 \%)$ had resection of a single lobe, $2(8.7 \%)$ had double lobectomy and $3(13.0 \%)$ had pneumonectomy. There was no reported postoperative mortality. One patient, however, developed bleeding, persistent air leak and aspiration pneumonia postoperatively, which required mechanical ventilation and an extended hospital stay. Three further patients were hospitalised for $>7$ days postoperatively. Following surgery, only two patients reported ongoing respiratory symptoms by day 90 . Microscopy of specimens from 22 of the resected lung sections identified fungal elements in 17 patients (73.9\%) (Table 4).

\section{Discussion}

We found that in a selected population with symptomatic and potentially resectable aspergillomas, only $47 \%$ underwent surgery. Resection of the involved lung is regarded as the most appropriate management strategy when the diagnosis of symptomatic aspergilloma is made and the patient is suitable for operation, ${ }^{[24,25]}$ with non-operative treatment having a limited role in such patients. In the context of massive haemoptysis, the risk-benefit assessment favours a surgical approach, with an observed 5 -year survival of $84 \%$ of subjects receiving lung resection, compared with $41 \%$ for those who do not, ${ }^{[10,26]}$ with some authors observing the development of invasive aspergillosis in $20 \%$ of nonsurgically treated cases. ${ }^{[4]}$ In the absence of massive haemoptysis, the indication for prophylactic surgical resection is less clear, with most authors suggesting observation of asymptomatic patients, and surgery only if symptoms develop. ${ }^{[27]}$

All our patients required surgical resection for symptomatic disease, yet the factors responsible for delays and lack of operations appeared complicated and multifactorial. On average, patients were given appointment dates at a median of 3 months after the multidisciplinary discussion, but waited twice as long for their surgery, while over a quarter of patients waited more than a year for their operation. We were unable to identify any unique predictors for the lack of surgical intervention, and there were no differences in geographical location, HIV status, respiratory physiology or the site of aspergillomas in the lung between those who underwent surgery 
and those who did not. We were therefore unable to identify any systematic patient factors that could act as barriers to surgery.

The factors responsible for delay in surgery and non-operation were probably the result of both institutional and personal factors, although in the majority of cases no reason was identified, with high rates of loss to follow-up. In our context, institutional factors such as shortage of thoracic surgical lists, and non-availability of hospital beds for elective thoracic surgical cases, play a significant role in delaying elective surgical procedures. The high rate of loss to follow-up is of concern, and it is unclear to what extent patient and clinical factors played a role. In cases where a reason for delay was identified, a wide range of reasons were given, including abatement of symptoms, miscommunication, lack of transportation to hospital, hospital bed shortage, refusal to consent, loss to followup, clinical worsening and lack of theatre time due to emergency procedures. Personal factors as a reason for loss to follow-up are more difficult to assess, and it is not clear to what extent patient frustration with the hospital system was responsible. When performed, surgery appeared relatively safe with no reported mortality, and was well tolerated with few complications, in keeping with multiple contemporary studies where mortality rates of $<1 \%$ were reported. ${ }^{[17-21]}$ Without surgery, mortality was high $(5.1 \%)$ and comparable to previous studies. ${ }^{[6-10]}$

Our study population was relatively young and predominantly male. Pulmonary tuberculosis (TB) was the most common identified underlying lung disease in our study population in keeping with high incidence of the condition in the general population. TB is said to have the highest incidence among the 25 - 34 year age group, and to be twice as common in men in the Cape Town Metropolis. ${ }^{[28,29]}$ Additionally, the low number of older patients in our study was likely due to selection bias, as older patients would have been less likely to be candidates for lung resection owing to greater surgical risk for a variety of reasons. Previous TB was, unsurprisingly, identified as the most likely underlying disease in our study population, owing to the extremely high background incidence of TB in our country. ${ }^{[30]}$ In some studies, $>50 \%$ of patients with $\mathrm{TB}$ developed pulmonary cavities following treatment, and $10-30 \%$ of these cavities are estimated to be complicated by chronic pulmonary aspergillosis, with the cavity size significantly associated with increased risk of developing aspergillosis. ${ }^{[31]}$

The proportion of patients with HIV in our study is comparable with the $\sim 19 \%$ prevalence of HIV in the general population of SA ${ }^{[32]}$ Remarkably, aspergillosis is unusual in patients with AIDS, ${ }^{[33]}$ which contrasts with the relatively high frequency of aspergillosis in most other seriously immunocompromised patients. For example, up to $70 \%$ of patients with leukaemia have pulmonary aspergillosis after 30 days of neutropenia. ${ }^{[34]}$ Nevertheless, the risk of developing TB is estimated to be between 26 and 31 times greater in people infected with HIV, making them susceptible to the development of aspergillomas. ${ }^{[35,36]}$

Unsurprisingly, upper lobectomy was the most common surgical procedure performed. This is consistent with both the usual distribution of residual tuberculous cavities and the reported literature. ${ }^{[10,22,36,37]}$

\section{Study limitations}

Firstly, it was a retrospective cohort, and thus depended exclusively on existing clinical records. Therefore, a number of variables of interest were not consistently identified, and some data were not uniformly captured by all clinicians over the 3 -year period. Secondly,

Table 3. Comparison between those resected and those not resected

\begin{tabular}{|c|c|c|c|}
\hline Characteristic & $\begin{array}{l}\text { Resected }(n=23), \\
n(\%)^{*}\end{array}$ & $\begin{array}{l}\text { Not resected }(n=27), \\
n(\%)^{*}\end{array}$ & $p$-value \\
\hline Age (years), median (IQR) & $46.6(40.5-49.8)$ & $41.9(32.6-49.8)$ & 0.1995 \\
\hline Sex, male & $15(65.2)$ & $16(59.3)$ & 0.665 \\
\hline Residence & & & 0.383 \\
\hline City of Cape Town & $11(47.8)$ & $16(59.3)$ & \\
\hline Cape Winelands & $12(52.2)$ & $9(33.3)$ & \\
\hline Symptoms & & & 0.908 \\
\hline Haemoptysis & $22(97.7)$ & $26(96.3)$ & \\
\hline Chest pain & $3(13.0)$ & $5(18.5)$ & \\
\hline Cough & $1(4.3)$ & $1(3.7)$ & \\
\hline Weight loss & 0 & $1(3.7)$ & \\
\hline Shortness of breath & 0 & $1(3.7)$ & \\
\hline Lobe involvement & & & 0.903 \\
\hline LUL & $11(47.8)$ & $14(51.9)$ & \\
\hline RUL & $10(43.5)$ & $10(37.0)$ & \\
\hline LUL + LLL & $1(4.3)$ & $1(3.7)$ & \\
\hline LLL & 0 & $1(3.7)$ & \\
\hline RUL + LLL & $1(4.3)$ & $1(3.7)$ & \\
\hline Type of disease & & & 0.670 \\
\hline Simple & $4(17.4)$ & $6(22.2)$ & \\
\hline Complex & $19(82.6)$ & $21(77.8)$ & \\
\hline Previous history of TB & $17(73.9)$ & $23(85.2)$ & \\
\hline HIV-positive & $5(21.7)$ & $6(22.2)$ & 0.956 \\
\hline FEV1 (L/s), median (IQR) & $1.86(1.63-2.13)$ & $1.88(1.51-2.42)$ & 0.7099 \\
\hline $\begin{array}{l}\text { Predicted \% FEV1, median } \\
\text { (IQR) }\end{array}$ & $56.1(51.2-73.0)$ & $65.5(49.1-76.6)$ & 0.4331 \\
\hline DLCO, median (IQR) & $16.2(14.4-20.6)$ & $16.0(14.8-18.1)$ & 0.8269 \\
\hline $\begin{array}{l}\text { Predicted \% DLCO, mean } \\
\text { (SD) }\end{array}$ & $59.6(55.7-72.3)$ & $58.6(51.8-71.4)$ & 0.6138 \\
\hline $\begin{array}{l}\mathrm{VO}_{2} \max (\mathrm{mL} / \mathrm{min} / \mathrm{kg}) \text {, } \\
\text { median (IQR) }\end{array}$ & $23.8(21.6-28.2)$ & $22.0(19.2-25.6)$ & 0.6484 \\
\hline
\end{tabular}


Table 4. Surgical outcomes for patients undergoing surgery

\begin{tabular}{ll}
\hline Characteristic & $\boldsymbol{n}(\%)^{\star}$ \\
\hline $\begin{array}{l}\text { Days to surgery, median (IQR) } \\
\text { Extent of resection }\end{array}$ & $190(134-351)$ \\
$\quad$ Lobectomy & $18(78.3)$ \\
Bi-lobectomy & $2(8.7)$ \\
$\quad$ Pneumonectomy & $3(13.0)$ \\
Complications & \\
Extended stay & $4(17.4)$ \\
Persistent air leak & $1(4.3)$ \\
Bleeding & $1(4.3)$ \\
Pneumonia & $1(4.3)$ \\
Histology, fungal elements present & $17(73.9)$ \\
*Unless otherwise specified. &
\end{tabular}

information on patient follow-up was not routinely documented or standardised for the majority of patients, and was obtained at non-standardised intervals. Finally, selection bias on the part of the attending physicians was possible, as only cases thought likely to be operable were presented at the multidisciplinary forum. To try to minimise these biases, we included all patients presented at the forum during the defined period, and created a standardised data extraction form for use on all patients.

\section{Study strengths}

Some of the study strengths were the 'real world' approach, i.e. not within the context of a controlled trial, which perhaps allowed a more insightful assessment of current usual practice over time. Similarly, the original data were collected by people other than the investigators, and were therefore independent of any specific hypothesis, diminishing observer bias. In addition, patients were presented in a multidisciplinary forum, which minimised the risk of errors in diagnosis.

\section{Conclusions}

Lung resection surgery remains the mainstay of therapy for pulmonary aspergilloma, yet in our context, less than half the patients fit for surgery underwent the operation, and waiting times were long (>1 year in 25\%) and were associated with mortality, highlighting the need for a patient-centred approach. Barriers to prompt surgery are complex, but should be addressed urgently.

Acknowledgements. We would like to acknowledge the Department of Biostatistics at Stellenbosch University, particularly Mr Chivanse, for his contribution in analysing the data.

1. Ayman OS, Pranatharthi HC. The clinical spectrum of pulmonary aspergillosis. Chest 2002;121(6):1988-1999. https://doi.org/10.1378/chest.121.6.1988

2. British Thoracic and TB Association. Aspergilloma and residual tuberculous cavities: The results of a resurvey. A report from the Research Committee of the British Thoracic and TB Association. Tubercle 1970;51(3):227-245. https://doi.org/10.1016/00413879(70)90015-2

3. Gefter WB. The spectrum of pulmonary aspergillosis. J Thorac Imaging 1992;7(4):5674. https://doi.org/10.1097/00005382-199209000-00009
4. Rafferty P, Biggs B, Crompton GK, Grant IW. What happens to patients with pulmonary aspergilloma? Analysis of 23 cases. Thorax 1983;38(8):579-583. https:// doi.org/10.1136/thx.38.8.579

5. Faulkner SL, Vernon R, Brown PP, Fisher RD, Bender HW. Hemoptysis and pulmonary aspergilloma: Operative versus nonoperative treatment. Ann Thorac Surg 1978;25(5):389-392. https://doi.org/10.1016/s0003-4975(10)63570-9

6. Glimp RA, Bayer AS. Pulmonary aspergilloma: Diagnostic and therapeutic considerations. Arch Intern Med 1983;143(2):303-308. https://doi.org/10.1001/ archinte.1983.00350020129023

7. Garvey J, Crastnopol P, Weisz D, et al. The surgical treatment of pulmonary aspergillomas. Thorac Cardiovasc Surg 1977;74(4):542-547.

8. Daly RC, Pairolero PC, Piehler JM, Trastek VF, Payne WS. Pulmonary aspergilloma. Results of surgical treatment. J Thorac Cardiovasc Surg 1986;92(6):981-988.

9. Karas A, Hankins JR, Attar S, et al. Pulmonary aspergillosis: An analysis of 41 patients. Ann Thorac Surg 1976;22(1):1-7. https://doi.org/10.1016/s0003-4975 (10)63943-4

10. Jewkes J, Kay PH, Paneth M, et al. Pulmonary aspergilloma: Analysis of prognosis in relation to haemoptysis and survey of treatment. Thorax 1983;38(8):572-578. https:// doi.org/10.1136/thx.38.8.572

11. Tuncel E. Pulmonary air meniscus sign. Respiration 1984;46(1):139-144. https://doi. org/10.1159/000194682

12. Denning DW, Cadranel J, Beigelman-Aubry C, et al. Chronic pulmonary aspergillosis: Rationale and clinical guidelines for diagnosis and management. Eur Res J 2016;47(1):45-68. https://doi.org/10.1183/13993003.00583-2015

13. Swanson KL, Johnson CM, Prakash UBS, McKusick MA, Andrews JC, Stanson AW. Bronchial artery embolization: Experience with 54 patients. Chest 2002;121(3):789795. https://doi.org/10.1378/chest.121.3.789

14. Corr P. Management of severe hemoptysis from pulmonary aspergilloma using endovascular embolization. Cardiovasc Intervent Radiol 2006;29(5):807-810. https:// doi.org/10.1007/s00270-005-0329-0

15. Belcher JR, Plummer NS. Surgery in broncho-pulmonary aspergillosis. Br J Dis Chest 1960;54(4):335-341. https://doi.org/10.1016/s0007-0971(60)80067-8

16. Walsh TJ, Anaissie EJ, Denning DW, et al. Treatment of aspergillosis: Clinical practice guidelines of the Infectious Diseases Society of America. Clin Infect Dis 2008;46(3):327-360. https://doi.org/10.1086/525258

17. Lejay A, Falcoz PE, Santelmo N, et al. Surgery for aspergilloma: Time trend towards improved results? Interact Cardiovasc Thorac Surg 2011;13(4):392-395. https://doi. org/10.1510/icvts.2011.265553

18. Chen QK, Jiang GN, Ding JA. Surgical treatment for pulmonary aspergilloma: A 35-year experience in the Chinese population. Interact Cardiovasc Thorac Surg 2012;15(1):77-80. https://doi.org/10.1093/icvts/ivs130

19. Kim YT, Kang MC, Sung SW, Kim JH. Good long-term outcomes after surgical treatment of simple and complex pulmonary aspergilloma. Ann Thorac Surg 2005;79(1):294-298. https://doi.org/10.1016/j.athoracsur.2004.05.050

20. Pratap H, Dewan RK, Singh L, et al. Surgical treatment of pulmonary aspergilloma: A series of 72 cases. Indian J Chest Dis Allied Sci 2007;49(1):23-27.

21. Brik A, Salem AM, Kamal AR, et al. Surgical outcome of pulmonary aspergilloma Eur J Cardiothoracic Surg 2008;34(4):882-885. https://doi.org/10.1016/j. ejcts.2008.06.049

22. Brunelli A, Charloux A, Bolliger CT, et al. ERS/ESTS clinical guidelines on fitness for radical therapy in lung cancer patients (surgery and chemoradiotherapy). Eur Respir J 2009;34(1):17-41. https://doi.org/10.1183/09031936.00184308

23. Von Groote-Bidlingmaier F, Koegelenberg CFN, Bolliger CT. Functional evaluation before lung resection. Clin Chest Med 2011;32(4):773-782. https://doi.org/10.1016/j. ccm.2011.08.001

24. Babatasi G, Massetti M, Chapelier A, et al. Surgical treatment of pulmonary aspergilloma: Current outcome. J Thorac Cardiovasc Surg 2000;119(5):906-912. https://doi.org/10.1016/s0022-5223(00)70085-7

25. Massard G, Roeslin N, Wihlm JM, et al. Pleuropulmonary aspergilloma: Clinical spectrum and results of surgical treatment. Ann Thorac Surg 1992;54(6):1159-1164. https://doi.org/10.1016/0003-4975(92)90086-j

26. Passera E, Rizzi A, Robustellini M, et al. Pulmonary aspergilloma. Clinical aspects and surgical treatment outcome. Thorac Surg Clin 2012;22:345-361. https://doi. org/10.1016/j.thorsurg.2012.04.001

27. Kousha M, Tadi R, Soubania O. Pulmonary aspergillosis: A clinical review. Eur Respir Rev 2011;20(121):156-174. https://doi.org/10.1183/09059180.00001011

28. Nyabadza F, Winkler D. A simulation age-specific TB model for the Cape Town metropole. S Afr J Sci 2013;109(9/10):1-7. https://doi.org/10.1590/sajs.2013/20120106

29. Austin JF1, Dick JM, Zwarenstein M. Gender disparity amongst TB suspects and new TB patients according to data recorded at the South African Institute of Medical Research laboratory for the Western Cape Region of South Africa. Int J Tuberc Lung Dis 2004;8(4):435-439. 
30. World Health Organization (WHO). Global TB Report 2014. Geneva: WHO, 2014:171.

31. De Vallière $\mathrm{S}$, Barker RD. Residual lung damage after completion of treatment for multidrug-resistant TB. Int J Tuberc Lung Dis 2004;8(6):767-771.

32. The Joint United Nations Programme on HIV/AIDS (UNAIDS). Fact Sheet 2015 UNAIDS Rep 2015;1-8.

33. Denning DW, Follansbee SE, Scolaro MM, Norris SS, Edelstein HH, Stevens DA Pulmonary aspergillosis in the acquired immunodeficiency syndrome. N Engl J Med 1991;324(10):654-662. https://doi.org/10.1056/nejm199103073241003

34. Schwartz RS, Mackintosh FR, Schrier SL, Greenberg PL. Multivariate analysis of factors associated with invasive fungal disease during remission induction therapy for acute myelogenous leukemia. Cancer 1984;53(3):411-419. https://doi. org/10.1002/1097-0142(19840201)53:3\%3C411:aid-cncr2820530308\%3E3.0.co;2-e

35. Getahun H, Gunneberg C, Granich R, Nunn P. HIV infection-associated TB: The epidemiology and the response. Clin Infect Dis 2010;50(S3):S201-207. https://doi. org/10.1086/651492

36. Selwyn P, Hartel D, Lewis V, et al. A prospective study of the risk of TB among intravenous drug users with human immunodeficiency virus infection. N Engl J Med 1989;320(9):545-550. https://doi.org/10.1056/nejm198903023200901

37. Denning DW, Riniotis K, Dobrashian R, Sambatakou H. Chronic cavitary and fibrosing pulmonary and pleural aspergillosis: Case series, proposed nomenclature change, and review. Clin Infect Dis 2003;37(S3):S265-S280. https://doi.org/10.1086/376526 